\title{
Design and analysis of microstrip antenna with zig-zag feeder for wireless communication applications
}

\author{
Malik Jasim Farhan, Ali Khalid Jassim \\ Electrical engineering Department, College of Engineering, Mustansiriyah University, Baghdad, Iraq
}

\begin{tabular}{l} 
Article Info \\
\hline Article history: \\
Received Jan 8, 2020 \\
Revised Dec 5, 2020 \\
Accepted Mar 24, 2021 \\
\hline
\end{tabular}

\section{Keywords:}

Feedline

Printed slot antenna

Ultra wide band

Zig-zag microstrip

\begin{abstract}
This paper is presented a microstrip antenna with a zig-zag feeder for wireless communication, it has a wideband frequency spectrum (2-14) GHz. The proposed antenna is designed with a zig zag feed line which gave a wideband frequency and acceptable gain (7.448-5.928) $\mathrm{dB}$, this antenna has zig zag slots printed in the ground plane on a lower side of the dielectric substrate, a certain form tuning stub is used to increase the matching between the feeder in the top layer of the substrate and ground plane in the bottom, this stub has an elliptical slot to performance matching input impedance with the feed line. The feeding technique used to feed this antenna is a strip feed line of $50 \Omega$. Different types of techniques are used to enhance the bandwidth of this antenna to get a wideband suitable for the requirements of the UWB antenna such as adjust the feed point position of the feed line with a tuning stub. All the radiation properties of the presented antenna are tested such as bandwidth, radiation pattern, and, gain.
\end{abstract}

This is an open access article under the $\underline{C C B Y-S A}$ license.

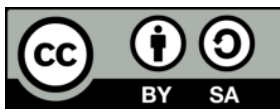

Corresponding Author:

Malik Jasim Farhan

Electrical Engineering Department, College of Engineering

Mustansiriyah University

Baghdad, Iraq

Email: malik.jasim@uomustansiriyah.edu.iq

\section{INTRODUCTION}

UWB is one of the wideband wireless technology approval by the "Federal Communication Committee" (FCC) from $3.1 \mathrm{GHz}$ to $10.6 \mathrm{GHz}$ frequency band, this technology attracted both academic and industrial communities' attention [1], [2]. The microstrip antenna can be suitable for UWB technology, especially the slot antenna which is consisted of a microstrip feed line and tuning stub in the top layer of substrate and a special slot in the ground plane at bottom of the substrate, this type of antenna is distinguished it has large magnetic near-fields make it does not attract nearby objects, unlike a patch antenna that tends to couple with objects nearby [3], [4]. The proposed antenna consists of a ground plane that has a slot with a certain shape that can be any shape printed on a lower side of a dielectric substrate, and on the opposite side of a dielectric substrate there is a zig-zag microstrip feedline with a tuning stub, but when the coplanar waveguide (CPW) used as a feeding technique the tuning stub and a slot on a ground plane printed on the same side of a substrate. This type of antenna has good features like those of low profile, lightweight, easy manufacturing, and has a large bandwidth so the speed of transferring the data is high [5]. Depending on the slot form, there are many types of this sort of antennas such as triangle, arc shape, circular, and rectangle, etc. Microstrip line or CPW may be used to feed these antennas [6]-[24].

In this paper, a new design of a zig-zag feeder microstrip antenna is proposed for wireless applications in the bandwidth of UWB. The proposed antenna consists of the ground plane of the slot printed on a lower side of a dielectric substrate and a rectangular tuning stub printed on the upper side of the 
dielectric substrate with elliptical slots. A zig-zag strip feedline of $50 \Omega$ connected to the port with a tuning stub for feeding. The purpose of using a tuning stub in a slot antenna is to increase the matching impedance between a feedline and a slot of the ground plane. A study of parametric is performed to calculate the best dimensions. There are some techniques used to improve the response of the slot antenna and get a wideband such as the feed point position technique and adjusting the feed gap distance between the lower edge of the tuning stub on an upper side of a substrate and a lower edge of the slot on the opposite side of the substrate.

\section{DESIGN OF ZIG-ZAG MICROSTRIP ANTENNA}

In the design of the zig-zag microstrip antenna, the first step is to calculate the size of a slot in the patch and ground that achieved the UWB requirement. It is found a slot in the antenna that the bandwidth's lower edge frequency can be found approximately by equating slot configuration area to that of cylindrical wire has radius $r$ and length $l$. The lower edge frequency $\left(f_{\mathrm{L}}\right)$ of bandwidth is given by [25]:

$$
\mathrm{f}_{\mathrm{L}}=\frac{30 \times C}{(l+r)}
$$

where $\mathrm{C}$ is an element factor, which can take values of 0.32 for an elliptical slot or 0.35 for a circular slot. These two values of $\mathrm{C}$ are evaluated and the first one is found appropriate for the slot, therefore,

$$
\mathrm{f}_{\mathrm{L}}=\frac{9.6}{(D+0.2785 D) \sqrt{\text { creff }}}
$$

where $1, \mathrm{r}, \mathrm{D}$ are all measured in centimeters.

According to (2) the value of $\mathrm{D}$ is $1.474 \mathrm{~cm}$, the tuning stub and a microstrip feedline of $50 \Omega$ are printed on Fr4 substrate has a relative permittivity $\left(\varepsilon_{\mathrm{r}}=4.4\right)$ and loss tangent $(0.0025)$, and a ground plane with a slot printed on the opposite side of a substrate with same dimensions of a substrate of the proposed antenna [25]. The width of the microstrip feed line is calculated $2.89 \mathrm{~mm}$ to achieve $50 \Omega$ characteristic impedance by using (3):

$$
\mathrm{Zc}=\frac{120 \pi}{\sqrt{\varepsilon \operatorname{reff}[\mathrm{Wf} / \mathrm{h}+1.393+0.667 \ln (\mathrm{Wf} / \mathrm{h}+1.444)]}}
$$

The tuning stub is used to improve the matching between a microstrip feedline and a slot.

\section{PARAMETRIC STUDY OF A PROPOSED ANTENNA}

This section has shown a parametric study and its effect on antenna performance.

\subsection{Effect of tuning stub dimensions}

The purpose of a tuning stub is the matching between the slot at the ground plane and a feedline on an upper side of a substrate. The dimensions of the rectangular tuning stub are tested. The best values of these dimensions were found by using the method of sweep parameter. Figures 1-3 are shown the variety of dimensions of tuning stub with frequency. The best values of these parameters are found at $\mathrm{TsL}=12 \mathrm{~mm}$, $\mathrm{TsW}=8 \mathrm{~mm}$, and $\mathrm{TsT}=2 \mathrm{~mm}$ respectively.

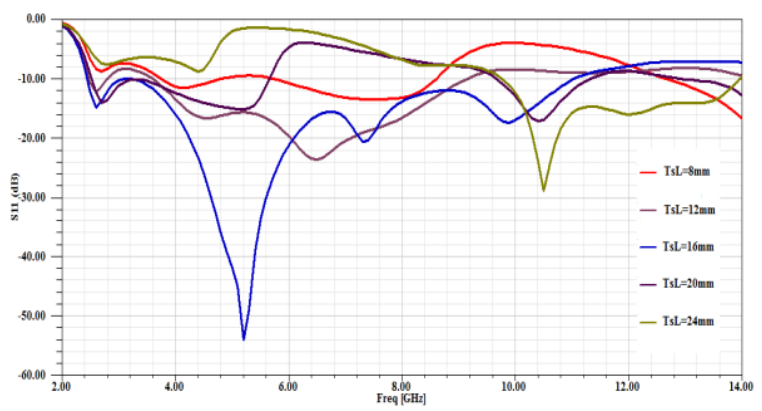

Figure 1. Variations of tuning stub length

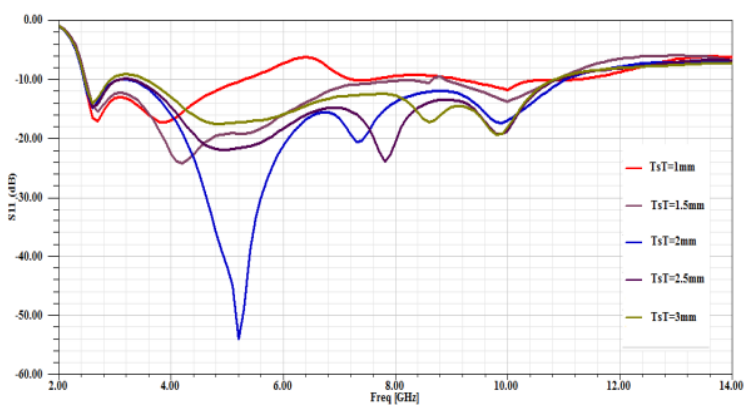

Figure 2. Variations of tuning stub thickness 


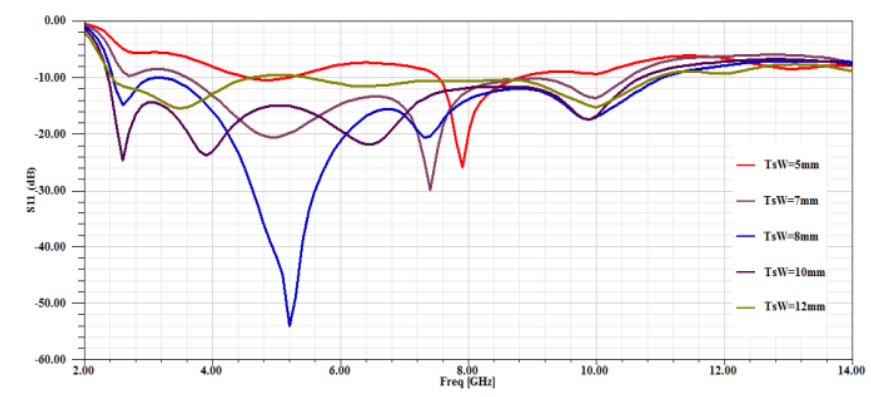

Figure 3. Variations of tuning stub width

\subsection{Effect of ground plane dimensions}

To find an optimum value of dimensions of the ground plane width (GW) and length (GL) these dimensions are tested. Figure 4 illustrates the simulated S11 of antenna and bandwidth for different values of a ground plane width $(\mathrm{GW})$. The optimum value of a width of a ground plane is found to be at $\mathrm{GW}=14 \mathrm{~mm}$. The simulated antenna S11 as a function of frequency for different values of a ground length (GL) as is shown in Figure 5. The response of the antenna is not affected by changing the length of the ground (GL). Figure 5 illustrates that the best value of GL is found as $10 \mathrm{~mm}$.

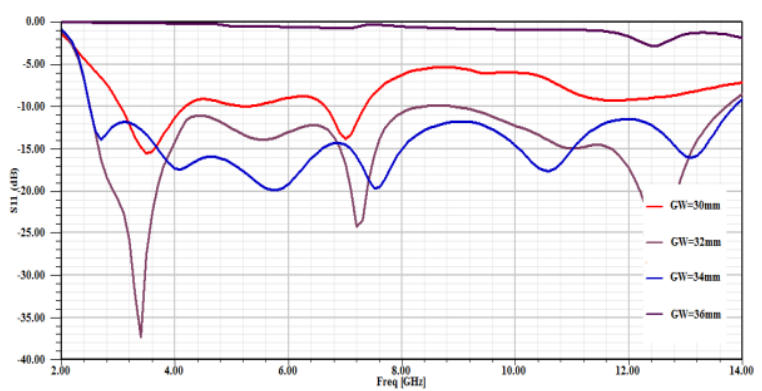

Figure 4. Variations of ground width

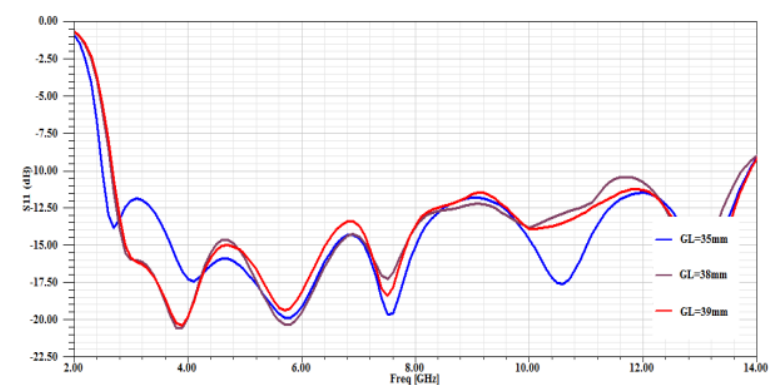

Figure 5. Variations of ground length

\subsection{The effect of feed point position}

Another parameter tested is the feed point position at this test the required is to find the connection point between the tuning stub and the zig-zag feed line to find the best matching impedance position. All points from the binding edge of the tuning stub to the edge of a tuning stub are tested and the best feed point is that achieved to determine the best matching impedance, the best value is $13 \mathrm{~mm}$ offset distance move from center, the Figure 6 shown the effect of feed point position on bandwidth.

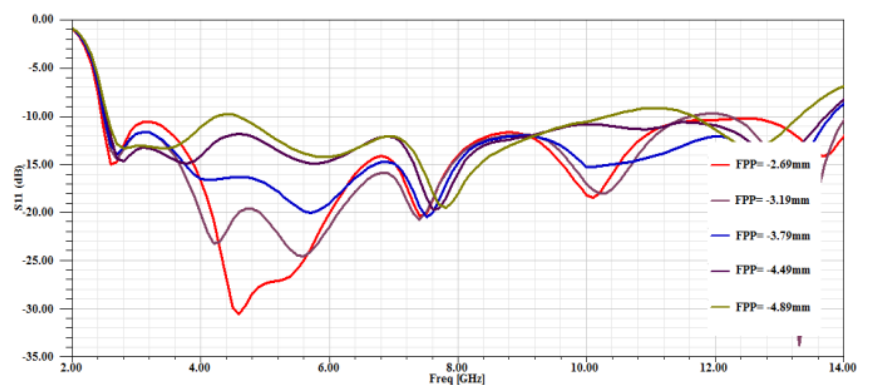

Figure 6. Variations of feed point position
Table 1. Parameters of optimal design of patch antenna

\begin{tabular}{lc}
\hline \multicolumn{1}{c}{ Parameter } & Value (mm) \\
\hline Substrate length (SL) & 14 \\
Substrate width (GW, SW) & 24 \\
Ground length (GL) & 10 \\
Ground width (GW) & 14 \\
Substrate thickness (h) & 1.6 \\
Feed point position (FPP) & 13 \\
The tilt angle of the feed & $45^{0}$ \\
Feed line width & 10 \\
Length of tuning stub (TsL) & 12 \\
Width of tuning stub (TsW) & 1 \\
Radius elliptic slot (Ry) & 1 \\
Radius elliptic slot (Rx) & 0.5 \\
\hline
\end{tabular}


The optimum values of all parameters affecting the performance of a proposed zig-zag microstrip antenna are presented in Table 1. Figure 7 shows the best antenna. Figure 8 shows the simulation $\mathrm{S}_{11}$ proposed antenna.

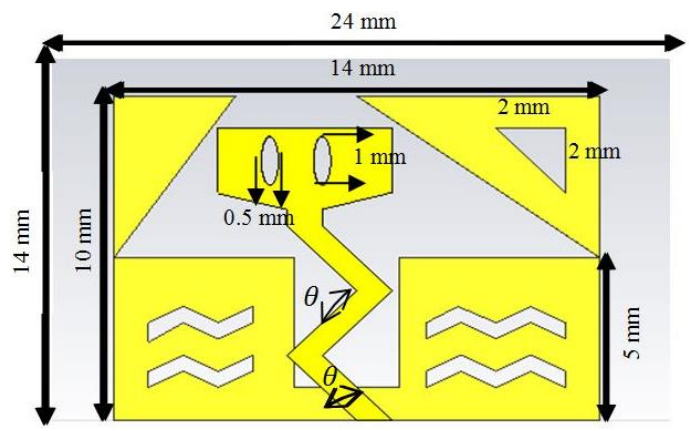

Figure 7. Proposed zig-zag antenna with its dimensions

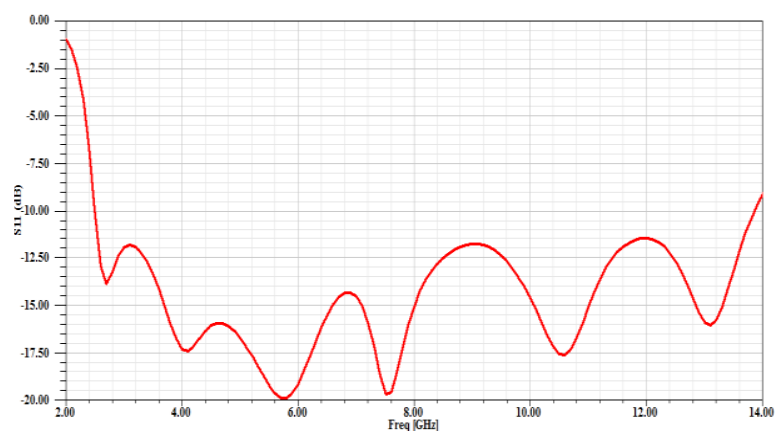

Figure 8. Simulation $\mathrm{S}_{11}$ proposed antenna

\section{THE RADIATION PATTERN OF A DESIGNED ANTENNA}

The simulated far-field radiation pattern of a proposed antenna is plotted. Figure 9 shows the total electric field $\mathrm{E}$ and magnetic field $\mathrm{H}$ at frequencies $3 \mathrm{GHz}$ in Figure 9(a) and 10.6 GHz in Figure 9(b). These patterns have omnidirectional properties at low frequencies and near omnidirectional radiation pattern at high frequencies.
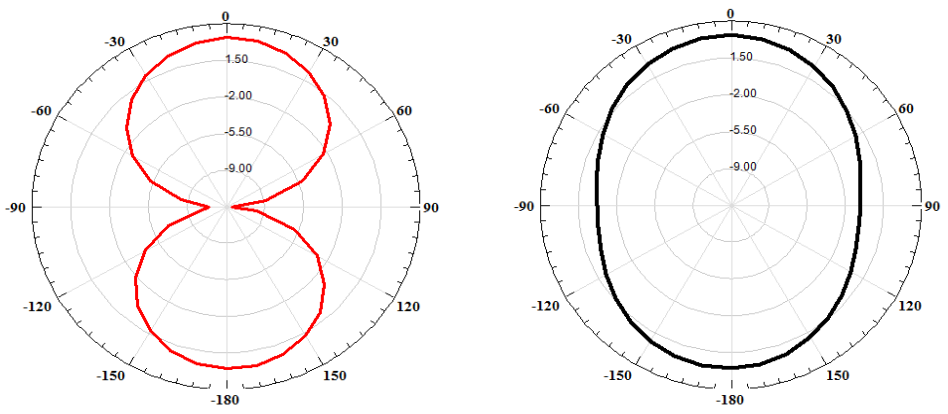

(a)
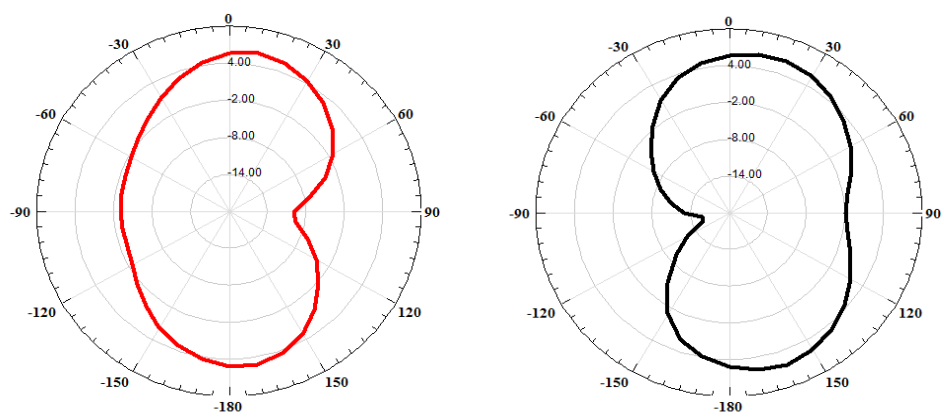

(b)

Figure 9. The radiation pattern E-plane and H-plane, (a) At $3 \mathrm{GHz}$, (b) At $10.6 \mathrm{GHz}$

\section{THE CURRENT DISTRIBUTION}

The simulated surface current distribution of the proposed antenna at frequencies $3 \mathrm{GHz}$ shows in Figure 10(a) and $10.6 \mathrm{GHz}$ are presented in Figure 10(b). From this figure the current is concentrated in the 
lower part of background, feeder and lower part diagonally of tuning stub at low frequency but the distribution of current is decreasing at these regions at high frequency, and that compatible with the radiation pattern where this pattern is omnidirectional at low frequency and directive at high frequency.

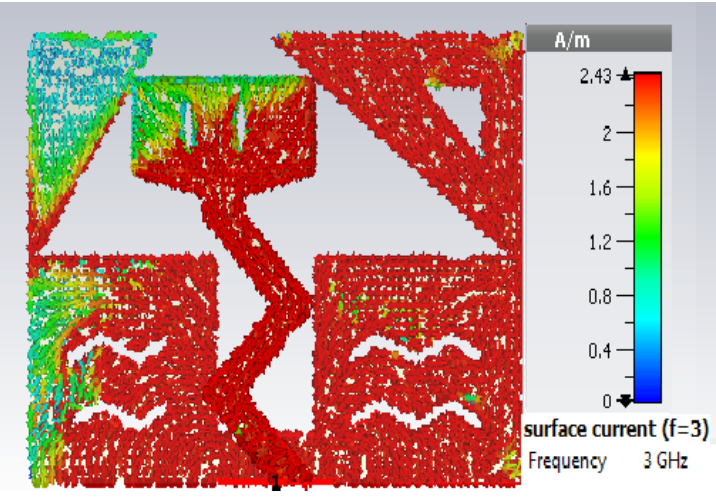

(a)

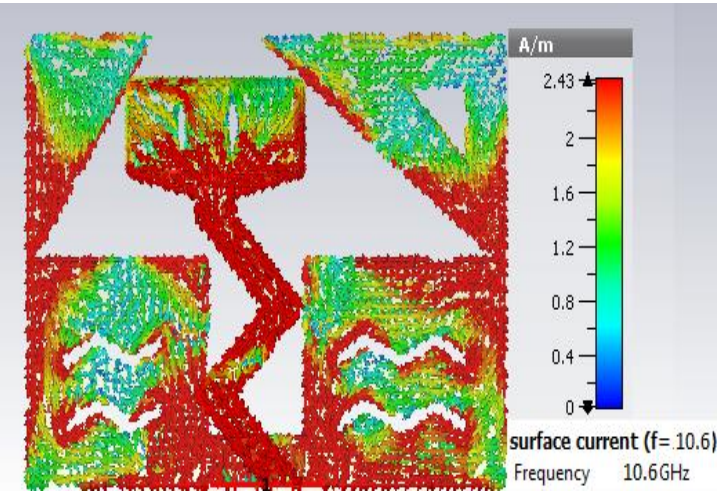

(b)

Figure 10. The current distribution of surface on an antenna structure, (a) At $3 \mathrm{GHz}$, (b) At $10.6 \mathrm{GHz}$

\section{ANTENNA GAIN}

Figure 11 illustrates the simulated gain versus frequency of a proposed antenna, which varies from $7.448 \mathrm{~dB}$ at $3.1 \mathrm{GHz}$ to $5.928 \mathrm{~dB}$ at $10.6 \mathrm{GHz}$. It is obvious that the gain of this antenna is compatible with result that concluded from current that distributed over the antenna surface, where high gain is realized when the current is concentrated in some regions of antenna surface, and it decreased when the current distributes more smoothly at high frequencies.

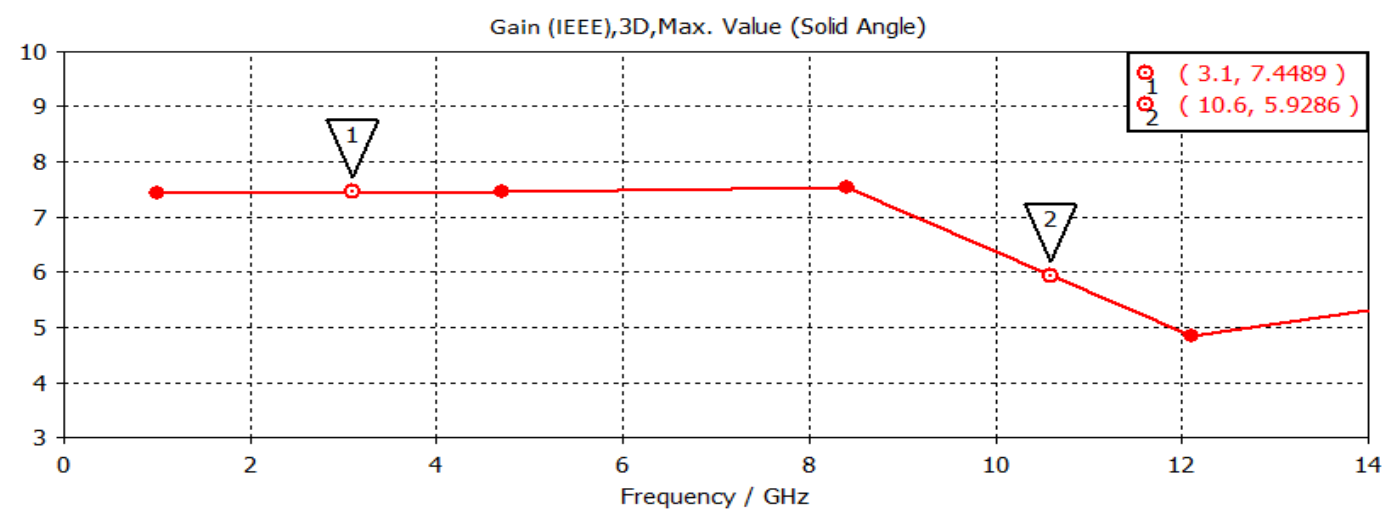

Figure 11. The simulated gain of a proposed UWB twisted microstrip antenna for different frequencies

\section{CONCLUSION}

A zig-zag microstrip antenna of small size and low-profile has been designed and analyzed in this paper to fulfill technological demands. This proposed antenna consists of a ground plane contain the slot printed on a lower side of a substrate and a zig-zag strip feedline of $50 \Omega$ with a tuning stub of rectangular shape printed on the patch side of a substrate with elliptical slots. The most significant parameters that affect the performance of an antenna are the dimensions of a slot that affects the lower edge of bandwidth and feed point position. The important thing in this design is a slot in a ground plane because it is the reason for the large bandwidth of the UWB antenna. The tuning stub is used to improve matching, therefore; the bandwidth becomes larger. The location of connection a feedline with the patch and zig-zag microstrip line effect on the bandwidth performance. 


\section{ACKNOWLEDGEMENTS}

The authors would like to thank Mustansiriyah University (www.uomustansiriyha.edu.iq) Baghdad Iraq for its support in the present work.

\section{REFERENCES}

[1] First Report and Order, "Revision of part 15 of the commission's rules regarding ultra-wideband transmission systems," Federal Communication Commission FCC, 02-48, April 22, 2002.

[2] A. K. Jassim, M. J. Farhan, and A. F. Fahad, "Design selective band antenna using coupling sidewall and multi resonator for wireless communications," Bulletin of Electrical Engineering and Informatics, vol. 9, no. 5, pp. 22062212, 2020, doi: https://doi.org/10.11591/eei.v9i5.2247.

[3] H. G. Schantz, "UWB magnetic antennas," IEEE Antennas and Propagation Society International Symposium, vol. 3, June 2003, pp. 604-607, doi: 10.1109/APS.2003.1219920.

[4] A. I. Al-Muttairi and M. J. Farhan, "Circular polarization reconfigurable antenna based on defect ground structure for mid-band 5G applications," International Journal on Communications Antenna and Propagation, vol. 10, no. 2, pp. 114-121, 2020, doi: 10.11591/ijeecs.v19.i2.pp802-810.

[5] T. Mandal and S. Das, "A coplanar waveguide fed ultra wideband hexagonal slot antenna with dual-band rejection," Progress In Electromagnetics Research, vol. 39, pp. 209-224, 2013, doi: 10.2528/PIERC13030701.

[6] J. Park, M. Jeong, N. Hussain, S. Rhee, P. Kim, and N. Kim, "Design and fabrication of triple-band folded dipole antenna for GPS/DCS/WLAN/WiMAX applications," Microw. Opt. Technol. Lett., vol. 61, no. 5, pp. 1328-1332, 2019, doi: 10.1002/mop.31739.

[7] J. Y. Chiou, J. Y. Sze, and K. L. Wong, "A broad-band CPW-fed strip-loaded square slot antenna," IEEE Transactions on Antennas and Propagation, vol. 51, no. 4, pp. 719-721, April 2003, doi: 10.1109/TAP.2003.812232

[8] Y. W. Jang, "Broadband cross-shaped microstrip-fed slot antenna," Electronics Letters, vol. 36, no. 25, pp. 20562057, Dec. 2000, doi: 10.1049/el:20001477.

[9] M. K. Kim, K. Kim, Y. H. Suh, and I. Park, "A T-shaped microstrip-line-fed wide slot antenna," IEEE Antennas and Propagation Society International Symposium, July 2000, vol. 3, pp. 1500-1503, doi: 10.1109/APS.2000.874491.

[10] S. Gino, F. Consoli, and S. Barbarino, "Numerical and experimental analysis of a circular slot antenna for UWB communications," Microwave and Optical Technology Letters, vol. 44, no. 5, pp. 465-470, March 2005, doi: 10.1002/mop.20669.

[11] E. A. Soliman, S. Brebels, E. Beyne, and G. A. E. Vandenbosch, "CPW-fed cusp antenna," Microwave and Optical Technology Letters, vol. 22, no. 4, pp. 288-290, August 1999, doi: 10.1002/(SICI)1098-2760(19990820)22:4< /288::AID-MOP21>3.0.CO;2-E.

[12] Y. F. Liu, K. L. Lau, Q. Xue, and C. H. Chan, "Experimental studies of printed wide slot antenna for wide-band applications," IEEE Antennas and Wireless Propagation Letters, vol. 3, no. 1, 2004, pp. 273-275, doi: 10.1109/LAWP.2004.837510.

[13] Ali Khalid Jassim and Raad H. Thaher. "Calculate the optimum slot area of elliptical microstrip antenna for mobile application," Indonesian Journal of Electrical Engineering and Computer Science, vol. 16, no. 3, pp. 1364-1370, Dec. 2019, doi: http://doi.org/10.11591/ijeecs.v16.i3.pp1364-1370.

[14] W-S. Chen and F. M. Hsieh, "Broadband design of the printed triangular slot antenna," IEEE Antennas and Propagation Society International Symposium, vol. 4, 20-25 June 2004, pp. 3733-3736, doi: 10.1109/APS.2004.1330158.

[15] J. S. Chen, "Dual-frequency annular-ring slot antennas fed by CPW feed and microstrip line feed," IEEE Transactions on Antennas and Propagation, vol. 53, no. 1, pp. 569-571, Jan. 2005, doi: 10.1109/TAP.2004.838799.

[16] J. Yeo, Y. Lee, and R. Mittra, "Wideband slot antennas for wireless communications," IEEE Proceedings of Microwaves, Antennas and Propagation, vol. 151, no. 4, pp. 351-355, August 2004, doi: 10.1049/ipmap:20040627.

[17] W-S. Chen, C. C. Huang, and K. L. Wong, "A novel microstrip-line-fed printed semicircular slot antenna for broadband operation," Microwave and Optical Technology Letters, vol. 26, no. 4, pp. 237-239, 2000, doi: https://doi.org/10.1002/1098-2760(20000820)26:4<237::AID-MOP10>3.0.CO;2-I.

[18] H-L. Lee, H. J. Lee, J. G. Yook, and H. K. Park, "Broadband planar antenna having round corner rectangular wide slot," IEEE Antennas and Propagation Society International Symposium, vol. 2, 16-21 June 2002, pp. 460-463, doi: 10.1109/APS.2002.1016122.

[19] L. Zhu, S. Sun, and W. Menzel, "Ultra-wideband (UWB) bandpass filters using multiple-mode resonator," IEEE Microw. Wirel. Components Lett., vol. 15, no. 11, pp. 796-798, 2005, doi: 10.1109/LMWC.2005.859011.

[20] J. Y. Sze and K. L. Wong, "Bandwidth enhancement of a microstrip-linefedprinted wide-slot antenna," IEEE Transactions on Antennas and Propagation, vol. 49, no. 7, pp. 1020-1024, July 2001, doi: 10.1109/8.933480.

[21] H. D. Chen, "Broadband CPW-fed square slot antennas with a widened tuning stub," IEEE Transactions on Antennas and Propagation, vol. 51, no. 8, pp. 1982-1986, August 2003, doi: 10.1109/TAP.2003.814747.

[22] R. Chair, A. A. Kishk, and K. F. Lee, "Ultrawide-band coplanar waveguide-fed rectangular slot antenna," IEEE Antenna and Wireless Propagation Letter, vol. 1, no. 3, pp. 227-229, 2004, doi: 10.1109/LAWP.2004.836580.

[23] A. Othman, N. I. S. Shaari, A. M. Zobilah, N. A. Shairi, and Z. Zakaria, "Design of compact ultra-wideband antenna for microwave medical imaging application," Indonesian Journal of Electrical Engineering and Computer Science, vol. 15, no. 3, pp.1197-1202, 2019, doi: http://doi.org/10.11591/ijeecs.v15.i3.pp1197-1202.

Design and analysis of microstrip antenna with zig-zag feeder for wireless... (Malik Jasim Farhan) 
[24] Abdullah A. Jabber, Ali Khalid Jassim, and Raad H. Thaher, "Compact reconfigurable PIFA antenna for wireless applications," TELKOMNIKA Telecommunication, Computing, Electronics and Control, vol. 18, no. 2, April 2020, pp. 595-602, 2020, doi: http://dx.doi.org/10.12928/telkomnika.v18i2.13427.

[25] Ali Khalid Jassim and Raad H. Thaher, "Design and analysis microstrip antenna with the reflector to enhancement gain for wireless communication," Bulletin of Electrical Engineering and Informatics, vol. 9, no. 2, pp. 652-660, April 2020, doi: https://doi.org/10.11591/eei.v9i2.1696.

\section{BIOGRAPHIES OF AUTHORS}

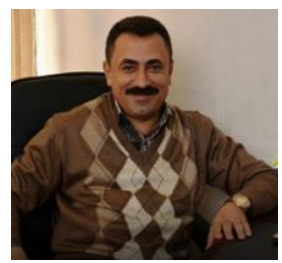

Asst. Prof. Dr. Malik Jasim Farhan at Mustansiriyah University, College of Engineering, held the position of Head of the Electrical Engineering Department in 2018 and became the Dean of the College of Engineering in 2019. He obtained a bachelor's degree in 1997, a master's degree in 2000, and a doctorate in 2015, specializing in communications engineering, and he works in the field of antennas. A large number of research published in international journals and conferences. E-mails: malikjf1974@gmail.com, malik.jasim@uomustansiriyah.edu.iq

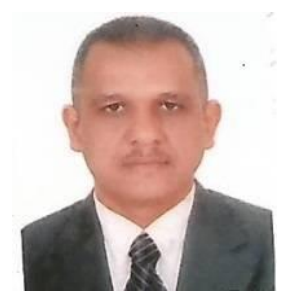

Asst. Prof Dr. Ali Khalid Jassim at Mustansiriyah University, college Engineering of Electrical Engineering Department. Holds a Bachelor's degree in 1999 and a Master's degree in 2010 and a Ph.D. in 2019 in communications engineering. Works in the field of cellular networks communications and antennas and has a many of research in international journals and scientific conferences. E-mail: alijassim79@yahoo.com, alijassim@uomustansiriyah.edu.iq, 